\title{
Aplicación práctica de la jurisdicción constitucional en el campo de la competitividad frente a la resolución de los conflictos de competencia en materia de tutela
}

\section{Practical application of constitutional jurisdiction in the field of competitiveness to the resolution of conflicts of jurisdiction in matters of action in protection of fundamental rights}

Rosembert Ariza Santamaría Doctor en Sociología Jurídica e Instituciones Políticas Profesor de la Facultad de Derecho Universidad Santo Tomás

Juan Carlos Delgado D’aste Magíster en Derecho Público U. Santo Tomás Universidad de Konstanz (Alemania) Profesor de la Facultad de Derecho - Universidad Santo Tomás

«Nunca podrá haber un Estado realmente libre e iluminado hasta que no reconozca al individuo como poder superior independiente del que derivan el que a él le cabe y su autoridad, y, en consecuencia, le dé el tratamiento correspondiente»

Henry D. Thoreau

\section{RESUMEN}

Se pretende en el presente análisis jurisprudencial establecer los elementos sobre el factor de competencia y los principios que a tal fenómeno rigen, igualmente el desarrollo del mismo, en torno a la acción de tutela y los conflictos que de suyo se han suscitado. Revisar las consideraciones y pronunciamientos tanto de la Corte Constitucional como de la Corte Suprema de Justicia, que permitan dilucidar un enfoque igualitario que desemboque en la unificación de criterios sobre el organismo competente para dirimir las colisiones de competencia fruto de la interposición del mecanismo fundamental.

\section{PALABRAS CLAVE}

Jurisdicción constitucional, acción de tutela, resolución de conflictos, competencia

\section{ABSTRACT}

It is intended in this jurisprudential analysis to establish the elements of the competition factor and the principles that govern this phenomenon, also its development, about the legal action and the conflicts that have arisen here. Review the considerations and pronouncements of both the Constitutional Court and the Supreme Court, that an egalitarian approach to elucidate leading to the unification of criteria on body to settle jurisdictional conflicts result of the filing of the underlying mechanism.

\section{KEYWORDS}

Constitutional jurisdiction, writ for protection of fundamental rights. conflict resolution, competition. 


\section{ACERCAMIENTO A LA ACCIÓN DE TUTELA}

El artículo 86 de la Norma Fundamental colombiana, expone en sus líneas el derecho encargado de la protección contra la vulneración y/o amenaza de los derechos fundamentales de la colectividad.

El amparo constitucional, así denominado en legislaciones como Alemania y México, este último "su país de origen, en donde fue establecido desde mediados del siglo XIX bajo la inspiración del habeas corpus" (Henao, 2010: 6), constituye una acción judicial subsidiaria, residual y autónoma que permite la protección inmediata de los ciudadanos frente a las acciones u omisiones de las autoridades públicas, y de manera excepcional de los particulares.

Ha sido regulado, además de la Constitución Política, fundamentalmente en normas tales como los Decretos 2591 de 1991 y 1382 de 2000, este último en materia de competencia. Para el efecto, la Corte Constitucional a partir de la sentencia T-001 de $1992^{1}$, definió de manera clara el concepto que hasta la fecha se entiende por acción de tutela, así:

La acción de tutela es un instrumento jurídico confiado por la Constitución a los jueces, cuya justificación y propósito consisten en brindar a la persona la posibilidad de acudir sin mayores requerimientos de índole formal y en la certeza de que obtendrán oportuna resolución, a la protección directa e inmediata del Estado, a objeto de que, en su caso, consideradas sus circunstancias específicas y a falta de otros medios, se haga justicia frente a situaciones de hecho que representen quebranto 0 amenaza de sus derechos fundamentales, logrando así que se cumpla uno de los fines esenciales del Estado, consistente en garantizar la efectividad de los principios, derechos y deberes consagrados en la Constitución.

Al respecto, el Consejo de Estado, actuando como juez constitucional, en sentencia del 10 de julio de 2013 se encargó de ilustrar la definición de acción de tutela en los siguientes términos:
En múltiples pronunciamientos de esta Corporación, y de la Corte Constitucional, se ha determinado la naturaleza legal y social de la acción de tutela, así denominada en nuestro ordenamiento jurídico, más aún, dentro de una cultura legal llamada a observar los postulados de la constitucionalización del derecho o neoconstitucionalismo ${ }^{2}$ como corriente postpositivista de la filosofía jurídica contemporánea. Dicha relación, y por los fundamentos existenciales de la acción de amparo, hace imperioso determinar que dicha herramienta es, sin duda alguna, uno de los pilares máximos sobre los cuales se estructura el nuevo constitucionalismo colombiano.

Ahora bien, la Corte Constitucional de Colombia, creada por la Constitución de 1991, se ha convertido en un órgano proteccionista y garantista de avanzada reconocida a nivel internacional, "prueba de ello la jurisprudencia laboral dentro del constitucionalismo social" (Dueñas, 2008, p.26) que funda en la acción de tutela un mandato concreto de interpretación y evolución de las garantías constitucionales, expresando un fuerte precedente fundamental bajo la existencia de una amplia gama de derechos ius constitucionales, que además de ser protegidos por ella, gozan de especial garantía con tal mecanismo tutelar.

En ese orden de ideas, es posible enmarcar a la acción de tutela como uno de los derechos y garantías con mayor efectividad y dinámica del diario jurídico del país en la actualidad, de donde se desprende el máximo respeto por el acceso efectivo a la administración de justicia.

Entre tanto, y en torno al procedimiento preferente y sumario de dicho mecanismo, como ya se anotó, el mismo se encuentra regulado por los Decretos 2591 de 1991, 306 de 1992 y 1382 de 2000, en donde el artículo cuarto del Decreto 306 de 1992, estatuyó que los vacíos 0 anomias encontrados dentro del procedimiento de tutela, podrán ser atiborrados por las normas conceptuadas dentro del Código de Procedimiento Civil, siempre y cuando no contraríen

1 M.P., Dr. José Gregorio Hernández Galindo.

2 "[E]ntendido como el término o concepto que explica un fenómeno relativamente reciente dentro del Estado constitucional contemporáneo". Fuente: Miguel Carbonell - Leonardo García Jaramillo Editores, "El Canon Neoconstitucional", Universidad Externado de Colombia, 2010, página 161. 
su propia naturaleza, incluyendo lo relacionado con las causales de nulidad procesal y a los conflictos de competencia. El referido artículo prescribe:

Para la interpretación de las disposiciones sobre trámite de la acción de tutela previstas por el Decreto 2591 de 1991 se aplicarán los principios generales del Código de Procedimiento Civil, en todo aquello en que no sean contrarios a dicho decreto (Art. 4).

\section{JURISDICCIÓN}

Una concepción amplia de Estado, supone la existencia de normas y preceptos que permiten el normal y correcto funcionamiento de la sociedad que en él habita. Para ello, a través de los tiempos, los Estados conforman sus propias constituciones, leyes, decretos, reglamentos, resoluciones, acuerdos, entre otros, que se encargan de regular la dinámica social de los ciudadanos.

En ese orden de ideas, el término jurisdicción ${ }^{3}$ se constituye como aquel órgano funcional encargado de aplicar las normas y reglamentos mencionados en el párrafo que precede, permitiendo así la aparición de uno de los poderes de los estados democráticos: El Poder Judicial.

En sentido amplio, la jurisdicción comporta la existencia de funcionarias y funcionarios, denominados jueces o magistrados, encargados de dirimir los conflictos suscitados entre los individuos, quienes acuden a ellos con el propósito de apelar en justicia la efectividad de sus derechos. Al respecto, Duverger (1968, p.205) explicó que "en virtud de este poder se dice que los jueces y magistrados pueden crear el derecho al mismo tiempo que lo aplican", dentro de aquellos casos que ameritan cierto tipo de interpretación, por la ambigüedad misma de la temática.

Igualmente, según lo enmarcó el profesor Naranjo Mesa (2010), es posible hablar de unidad 0 multiplicidad de jurisdicciones, es decir, que en algunas legislaciones las diferentes actividades jurisdiccionales se han atribuido a una misma jurisdicción, la cual conoce multiplicidad de conflictos dentro de las áreas del derecho, llámese derecho penal, civil, administrativo, entre otros. Por otro lado, en países como Colombia, existe una jurisdicción para cada especialidad jurídica, en donde podemos encontrar a la Corte Suprema de Justicia como máximo órgano de las ramas civil, penal y laboral; el Consejo de Estado, como corporación de cierre de la Jurisdicción Contencioso Administrativa y máximo cuerpo consultivo del Gobierno Nacional; la Corte Constitucional, encargada, además de la guarda de la Constitución, de revisar la totalidad de fallos de tutela proferidos por las y los jueces de la República y decidir bajo su libre potestad la selección de aquellos asuntos de trascendencia y relevancia constitucional; finalmente, el Consejo Superior de la Judicatura, Sala Jurisdiccional Disciplinaria, como máximo órgano de los procesos en contra de los funcionarios de la Rama Judicial y abogados en ejercicio.

\subsection{Jurisdicción constitucional}

Descrito el anterior concepto sobre jurisdicción en sentido amplio, es menester establecer los criterios identificadores de la llamada: "jurisdicción constitucional'. Para el efecto, se hace necesario iniciar este aparte con la definición que hiciere Lautaro Ríos Álvarez citada por Ana Giacomette Ferrer en "La Prueba de los Procesos Constitucionales", así:

Con mucha razón, que la jurisdicción constitucional es la potestad decisoria atribuida por la Constitución a uno 0 más órganos jurisdiccionales con la precisa misión de resguardar y hacer prevalecer el principio de supremacía de la Constitución en todas 0 en algunas de sus manifestaciones.

Bajo ese aspecto, se tiene que la Constitución Política de Colombia de 1991, estableció en el Título VIII, Capítulo IV, artículos 239 a 245, la denominada Jurisdicción Constitucional, en donde le confiere a la Corte Constitucional la misión de la guarda de la integridad y supremacía de aquella. 
Así las cosas, se entiende, desde un sentido bastante profundo, la existencia de una jurisdicción constitucional que se encarga de velar por el idóneo y eficaz proceder de las instituciones del Estado con relación a los particulares, y por qué no, la relación misma entre las y los ciudadanos, quienes sin duda alguna están igualmente sometidos al imperio de la Constitución.

Desde el punto de vista orgánico, la aplicación de la jurisdicción constitucional reviste, a criterio de los autores, el mayor grado de complejidad entre la definición global de jurisdicción y la conformación de la misma desde el ámbito constitucional de Colombia. Lo anterior, en virtud de las múltiples interpretaciones que sobre el asunto se han suscitado, unas, que propenden por la creación de juezas y jueces encargados de dirimir exclusivamente asuntos de naturaleza eminentemente constitucional, tales como las acciones de tutela, acciones populares y de grupo, acciones de cumplimiento, habeas corpus, entre otros; y por otro lado, quienes optan por la posición de investir a la totalidad de juezas y jueces como parte de la jurisdicción constitucional, entidad brindada con ocasión del conocimiento de las acciones de tutela a la totalidad de los operadores judiciales de la Rama Jurisdiccional.

Ahora bien, gracias a la constitucionalización del derecho, se tiene que no sólo los procesos que derivan su existencia de una norma de carácter constitucional pertenecen precisamente a ella, sino por el contrario, todos y cada uno de los asuntos que conoce la esfera judicial hacen parte del Derecho Constitucional, en tanto resuelven conflictos de ciudadanas y ciudadanos que se encuentran protegidos por el Estado por el simple, pero importantísimo hecho, de salvaguardar la dignidad humana de cada uno de ellos. Bajo ese contexto, señalamos, por ejemplo, que dentro de un proceso ejecutivo de mínima o menor cuantía, en principio es un asunto eminentemente económico, sin embargo, el mismo encuentra su principal teleología en seres humanos, quienes efectivamente acuden a la justicia para que sea ella la encargada de dirimir sus diferencias, independientemente del origen 0 jurisdicción de la misma.

\section{COMPETENCIA}

Ahora bien, en cuanto al tema de competencia judicial, se entiende que es aquella capacidad, tanto funcional como territorial, que el Estado confiere a determinados funcionarios con el fin de que éstos ejerzan la respectiva jurisdicción. Al respecto, la Corte Constitucional, en la sentencia C-040 de 1997, ha considerado:

La competencia de una autoridad judicial ha sido entendida como la porción, la cantidad, la medida 0 el grado de la jurisdicción que corresponde a cada juez o tribunal, mediante la determinación de los asuntos que le corresponde conocer, atendidos determinados factores (materia, cuantía, lugar, etc). ${ }^{4}$

Acudiendo a la doctrina, en palabras del profesor Ugo Rocco, la competencia puede definirse como "[a]quella parte de jurisdicción que corresponde en concreto a cada órgano jurisdiccional singular, según criterios a través de los cuales las normas procesales distribuyen la jurisdicción entre los distintos órganos ordinarios de ella." (Rocco, 1972, p. 41).

Entonces, la competencia es la facultad que en concreto está atribuida por la ley a cada uno de las funcionarias y funcionarios judiciales, teniendo en cuenta un cierto tipo de factores, como el territorial, funcional, entre otros, que garantizan que el asunto debatido, será conocido por el juez correspondiente.

De esta manera, se hallan en el ordenamiento procesal colombiano, empleadas y empleados judiciales que tienen la capacidad de realizar determinadas actuaciones en un determinado territorio, pues han sido investidos por parte del Estado, por una idoneidad específica que les permite ejercer sus funciones dentro de los límites que la misma Nación demarca. Por lo tanto, si ejercen actos diferentes 0 por fuera del territorio

4 CConst, C-040/1997, A. Barrera. 
asignado, estarían entonces obrando por fuera de su competencia y sus actuaciones carecerían de valor jurídico.

En este sentido, la Corte Constitucional en sentencia C-111 de 2000, determinó:

La asignación legal de una competencia a una autoridad judicial supone la determinación acerca del ejercicio de una función pública, en desarrollo del mandato establecido en el artículo 150-23, en virtud del cual corresponde al Congreso de la República `expedir las leyes que regirán el ejercicio de las funciones públicas', siendo en este caso la administración de justicia la función pública regulada, la cual de conformidad con lo señalado en el artículo 228 de la Ley Fundamental, constituye materia de ley para su organización y realización, de manera pronta y eficiente. ${ }^{5}$

Ahora bien, para efectos de fijar la competencia, se deben tener en cuenta diversos factores, los cuales han sido definidos así: objetivo, que encuentra su fundamento en la naturaleza del proceso y en la cuantía de la pretensión; subjetivo, que atiende la calidad de la persona que interviene en el proceso; funcional, que se determina en razón del principio de la doble instancia; territorial, relacionado con el espacio en el cual un funcionario judicial ejerce sus funciones, es decir, lugar o territorio para desatar los litigios que en él surjan; y por último, el factor de conexión, es decir, cuando en razón de la acumulación de una pretensión a otra, entre las que existe conexión real, un juez, que en principio no es competente para conocer de ellas, a razón de tal factor, puede llegar a serlo.

Así mismo, por regla general, la competencia se rige por los principios de legalidad, imperatividad, inmodificabilidad e indelegabilidad, respecto de los cuales, el máximo órgano constitucional de Colombia, expresó:

Legalidad, porque es determinada por la ley; imperatividad, porque no es derogable por la voluntad de las partes ni de las autoridades; inmodificabilidad por cuanto no se puede variar en el curso de un proceso (perpetuatio jurisdictionis); indelegabilidad, ya que no puede ser transferida por quien la detenta; y es norma de orden público puesto que se funda en principios de interés general. ${ }^{6}$

En ese orden de ideas, se puede concluir que todos los jueces y juezas poseen jurisdicción, más no competencia. De este modo, se afirma que la competencia no puede ser algo optativo de las partes, por el contrario, debe ser no sólo observado por los usuarios de la administración de justicia, sino por el juez del conocimiento, para que las posteriores decisiones no adolezcan de vicios de nulidad procesal, y por ende un desgaste injustificado del aparato judicial.

Con respecto a la legislación, existe el Pacto Internacional de Derechos Civiles y Políticos el cual señala en su artículo 14:

Todapersonatendráderechoaseroídapúblicamentey con las debidas garantías por un tribunal competente, independiente e imparcial establecido por la ley, en la substanciación de cualquier acusación de carácter penal formulada contra ella o para la determinación de sus derechos u obligaciones de carácter civil.

A su turno, la Convención Americana sobre Derechos Humanos establece en su artículo 8:

Toda persona tiene derecho a ser oída, con las debidas garantías y dentro de un plazo razonable, por un juez o tribunal competente, independiente e imparcial, establecido con anterioridad por la ley, en la sustanciación de cualquier acusación penal formulada contra ella, o para la determinación de sus derechos y obligaciones de carácter civil, laboral, fiscal o de cualquier otro carácter.

Finalmente, la Constitución Política de Colombia, consagra en su artículo 29 que "[n]adie podrá ser juzgado sino conforme a leyes preexistentes al acto que se le imputa, ante juez o tribunal competente y con observancia de la plenitud de las formas propias de cada juicio".

5 CCons, C-111/2000, Á. Tafur.

6 CCons, C-1541/2000, C. Gaviria. 


\section{POSICIÓN CORTE CONSTITUCIONAL}

Luego de establecer los elementos sobre el factor de competencia y los principios que a tal fenómeno rigen, se analizará cuál ha sido el desarrollo del mismo, en torno a la acción de tutela y los conflictos que de suyo se han suscitado.

Así las cosas, el Decreto 2591 de 1991, en su artículo 37, consagró un tipo de competencia específico, en donde atribuyó el conocimiento del derecho de amparo, a la totalidad de los jueces integrantes de la Rama Judicial, estableciendo:

A prevención, los jueces o tribunales con jurisdicción en el lugar donde ocurriere la violación o la amenaza que motivaren la presentación de la solicitud. El que interponga la acción de tutela deberá manifestar, bajo la gravedad del juramento, que no ha presentado otra respecto de los mismos hechos y derechos. Al recibir la solicitud, se le advertirá sobre las consecuencias penales del falso testimonio. De las acciones dirigidas contra la prensa y los demás medios de comunicación serán competentes los jueces de circuito del lugar.

Sin embargo, tal decisión del legislativo, no conceptualizó un panorama amplio en cuanto a los conflictos de competencia que entre los jueces mencionados puedan suscitarse, en tanto que al darle competencia a la generalidad de los funcionarios judiciales, (además de permitirle al actor tutelar, interponer la acción constitucional en cualquier tipo de jurisdicción sin importar la causa de fondo del petitum fundamental) generaría cierto tipo de conflictos entre aquellos operadores que declararan su incompetencia. Tal situación, parecería haber sido solucionada, toda vez que si la acción de tutela fue interpuesta en la jurisdicción civil, sería ésta la encargada de dirimir el conflicto de competencia que se presente, pero, ¿qué hacer cuando el conflicto surge en jurisdicciones diferentes?, verbigracia, el enfrentamiento entre la jurisdicción civil y su homónima en lo penal.

A partir de tal concepción, y con el fin de resolver el interrogante planteado, es necesario reconocer la importancia de los autos emitidos por la Corte Constitucional de Colombia, con relación a la temática hoy planteada. Para ello, las siguientes líneas tratarán sobre los referidos autos, de los cuales se realizará un minucioso estudio de la posición de la Corte Constitucional desde el mismo momento de su creación, hasta la fecha.

Dicho así, se iniciará mencionando el Auto 014 de 1994, en donde la Corte Constitucional, por primera vez abordó el tema objeto de estudio. El debate que hiciere el máximo órgano constitucional en esta ocasión, inicia en responder a la pregunta: ¿qué debe hacer el juez cuando se declare incompetente para conocer una acción de tutela?, para lo cual adhiriendo su jurisprudencia a lo dispuesto por la Corte Suprema de Justicia, en un auto de marzo de 1994, concluyó:

Si el juez de tutela se considera incompetente, el procedimiento a seguir por su parte es rechazar la demanda y ordenar su devolución al interesado, pues sólo a él le corresponde decidir ante cuál juez presenta su acción. La limitación que existe se refiere a que no puede hacerlo ante la Corte Constitucional, Corte Suprema de Justicia, Consejo de Estado, 0 ante el Consejo Superior de la Judicatura, por no ser posible tramitar la segunda instancia. Y tampoco presentarla ante la Justicia Penal Militar, por las razones expuestas en el auto de esta Corte, de fecha 10. de agosto de 1994, Sala Primera de Revisión. ${ }^{7}$

Sin embargo, un año después de tal pronunciamiento, mediante Auto 017 de 1995, la Corte consideró que existen dos sentencias discordantes, que soportan interpretaciones igualmente contradictorias. En primer lugar, en el año 1994, señaló:

Las jurisprudencias que admiten que los jueces de tutela, cuando no se consideran competentes para conocer a causa del factor territorial, en vez de devolver las demandas, están facultados para enviarlas a los despachos supuestamente competentes. En estos casos, es claro, si los destinatarios discrepan del criterio de los remitentes, necesariamente habrá conflictos de competencia.

7 CCons, Auto 014/1994, e37837. J, Arango 
En este grupo está la sentencia T-591 del cuatro (4) de diciembre de mil novecientos noventa y dos (1992), proferida por la Sala de Revisión integrada por los magistrados Jaime Sanín Greiffenstein, Ciro Angarita Barón y Eduardo Cifuentes Muñoz.

Este fallo confirmó una sentencia dictada por la Sala Penal del Tribunal Superior del Distrito Judicial de Santafé de Bogotá, D.C. Pero lo que realmente interesa destacar, es el hecho de que no obstante que en esta acción de tutela el tribunal avocó el conocimiento por remisión del Juzgado Único Civil del Circuito de Pamplona (Norte de Santander) -que no se consideró competente por el factor territorial, habida cuenta de que el lugar de la violación del derecho alegado era Santafé de Bogotá, lugar donde tenía y tiene su sede la autoridad demandada, a saber, el H. Consejo de Estado-, la Corte Constitucional, aun cuando revisó el negocio centrando su atención en otros temas, prima facie no vio en la conducta del juzgado algo contrario al ordenamiento jurídico. En otras palabras, no devolver la demanda al actor $y$, más bien, enviar las diligencias al juez competente, no fue considerado, en principio, como un proceder equivocado. ${ }^{8}$

Además del anterior pronunciamiento, trajo a colación la Sentencia T-162 de 1993, dictada por la Sala de Revisión de los magistrados Carlos Gaviria Díaz, José Gregorio Hernández Galindo y Hernando Herrera Vergara.

Posteriormente, citó el auto de la Sala Plena de esa misma Corporación número dieciséis 016 de 1994 que no "solamente aceptó que los conflictos de competencia sí pueden darse en la jurisdicción constitucional, sino que resolvió uno suscitado entre el Tribunal Superior del Distrito Judicial de Villavicencio y el Tribunal Contencioso Administrativo del Meta." Igualmente, dentro del mismo Auto, anotó:

La Sala Jurisdiccional Disciplinaria del H. Consejo Superior de la Judicatura, en providencia del tres (3) de febrero de mil novecientos noventa y cuatro (1994), admitió la posibilidad de los conflictos de competencia en la jurisdicción constitucional. En lo pertinente dijo:

Entonces, no se remite a dudas que la acción de tutela se tramita dentro de la Jurisdicción Constitucional, que se encuentra a cargo de todos los jueces de la República sin excepción, cuyos fallos son impugnables ante el superior jerárquico. $Y$ de esto se sigue obviamente que si dos jueces discuten la competencia sobre una tutela, lo hacen dentro de la Jurisdicción Constitucional de la cual ambos forman parte, y que tal conflicto será un conflicto de competencia, pero nunca un conflicto de jurisdicción porque, como la Corte Constitucional lo señaló, cuando un juez se halla frente a una acción de tutela, en ese momento no está actuando como Juez de la materia a la cual pertenece "sino como Juez Constitucional.

En segundo lugar, estableció aquellas sentencias, que sostienen que el juez incompetente debe proceder a la devolución de la demanda. Para tal efecto, en el mismo Auto estableció: "[l]a consecuencia obvia de estas jurisprudencias es impedir 0, por lo menos, limitar el que las incompetencias territoriales de jurisdicción puedan ser resueltas judicialmente. De ahí la oposición con las anteriores decisiones."

En esta categoría está la sentencia T-436 del treinta (30) de septiembre de mil novecientos noventa y cuatro (1994), dictada por la Sala de Revisión conformada por los magistrados Jorge Arango Mejía, Antonio Barrera Carbonell y Eduardo Cifuentes Muñoz. Allí, en la parte pertinente, se lee:

(...) cuando un juez o tribunal estime que es incompetente para conocer del asunto por el factor territorial, y ante la falta de reglamentación expresa sobre el procedimiento a seguir, lo pertinente es devolver la demanda al actor, indicándole el lugar en donde debe proponer su acción, para que éste elija cualquier juez dentro de dicha jurisdicción territorial.

Finalmente, concluyó el Alto Tribunal:

La regla que afirma que el juez que basado en consideraciones relacionadas con el factor territorial,

8 CCons, Auto 017/1995, e37837. J, Arango.

9 Ibídem. 
no cree ser competente para conocer de una determinada acción de tutela, debe proceder al envío inmediato de la actuación al que en su concepto sí tiene competencia, es la más ajustada a derecho.

La anterior decisión, fundamentó su existencia en el uso del método analógico, aclarando que el artículo 37 del Decreto 2591 de 1991:

Guardó silencio sobre la conducta que los juzgadores de primera instancia deben seguir cuando la parte actora, por desconocimiento de las reglas de la competencia territorial, demanda donde no corresponde. Ello significa, ni más ni menos, que sobre este particular no hay disposición expresa en la ley.

Seguidamente, recordó, luego de citar las normas que regulan la analogía jurídica, que:

Es menester encontrar la disposición respecto de la cual pueda operar tal método. En este caso, a juicio de la Sala, tal norma no es otra distinta del inciso primero del artículo 148 del Código de Procedimiento Civil. ¿Por qué?

Porque allí se ordena que "siempre que el juez declare su incompetencia para conocer de un proceso, ordenará remitirlo al que estime competente dentro de la misma jurisdicción" (negrillas por fuera de texto).

Como se ve, puesto que el juez civil que no estima ser competente, no está facultado para devolver el proceso a la parte interesada, sino que, por el contrario, debe remitirlo a quien estime competente, por analogía, el juez de tutela que se halle en similar situación, también tiene que proceder al envío de la actuación al juzgador competente.

Además de la anterior justificación, la Corte Constitucional soportó su decisión en el desarrollo del derecho fundamental al libre acceso a la administración de justicia, precisando que la Rama Judicial excepcionalmente puede negarse a conocer los asuntos judiciales propuestos por las y los ciudadanos en virtud del artículo 37 del Código de Procedimiento Civil, en tanto que es ampliamente conocido que el juez tiene la obligación de fallar Ios conflictos, incluso, con ausencia de legislación aplicable al caso concreto.
Bajo ese aspecto, la Corte consideró que el hecho de no existir legislación concreta frente al tema preciso de competencias, no pueden los jueces abstenerse del conocimiento de las acciones interpuestas por las y los ciudadanos, razón por la cual, deben éstos fallar tales asuntos. Para finalizar, en cuanto a la autoridad competente para dirimir los conflictos en materia de tutela, el máximo Tribunal Constitucional, reseñó:

En términos generales, cuando, con ocasión del trámite de acciones de tutela, cualquier juez 0 tribunal de la jurisdicción constitucional se vea en la necesidad de decidir sobre un conflicto de competencia originado en consideraciones de orden territorial o material, deberá hacerlo apoyándose en las disposiciones ordinarias vigentes, las cuales son perfectamente aplicables por analogía, con excepción de los conflictos entre tribunales de distrito judicial y tribunales administrativos, casos en los cuales la decisión corresponde a esta Corte Constitucional, pues los superiores de esas autoridades en desacuerdo -el H. Consejo de Estado y la H. Corte Suprema de Justicia- tienen igual jerarquía.

Seguidamente, por medio de Auto 020 de 1996, luego de la expedición de la Ley Estatutaria de la Administración de Justicia (Ley 270 de 1996), la Corte Constitucional, expresó que en concordancia con el artículo 241, numeral 9, de la Constitución Política, es ella competente para revisar las providencias judiciales que se profieran en relación con el ejercicio de la acción de tutela. En ese sentido, manifestó:

Como se puso de presente en auto del 5 de abril de 1995 (M.P.: Dr. Jorge Arango Mejía), aplicando analógicamente las normas procesales generales sobre resolución de conflictos de competencia, ante la inexistencia de una norma expresa en el Decreto 2591 de 1991, a esta Corte, en su condición de máximo tribunal de la jurisdicción constitucional, le corresponde decidir sobre los conflictos de competencia originados en órganos pertenecientes a distintas jurisdicciones que, al administrar justicia en el campo de la acción de tutela, hacen parte de aquélla.

Ello resulta todavía más claro si se tiene en cuenta lo expresado por el artículo 43 de la Ley 270 de 
1996 (Estatutaria de la Administración de Justicia), en el sentido de que `también ejercen jurisdicción constitucional, excepcionalmente, para cada caso concreto, los jueces y corporaciones que deban proferir las decisiones de tutela o resolver acciones 0 recursos previstos para la aplicación de los derechos constitucionales'. ${ }^{10}$

Tal concepción fue reiterada por numerosos Autos proferidos en la misma época, por ejemplo, en Auto 044 de 1998, en donde la Corte Constitucional consideró que aquella se encarga de resolver conflictos de competencia cuando éstos devienen de jueces que no tienen un superior jerárquico común, toda vez que es dicho superior el encargado de dirimir la colisión planteada, independientemente de si la misma es positiva o negativa.

Igualmente, tal y como ut supra fue descrito, cuando se intentó definir el concepto de jurisdicción constitucional, el auto en cita recalcó que todos los jueces de tutela, independientemente de la jurisdicción a la cual pertenezcan, hacen parte -para los fines de la actividad judicial propios de aquélla- de la jurisdicción constitucional.

Por lo tanto, los conflictos que surjan entre ellos deben ser resueltos dentro de la misma jurisdicción constitucional, lo que hace que en esta materia no resulte aplicable el artículo 256, numeral 6, de la Carta Política, que atribuye al Consejo Superior de la Judicatura -Sala Jurisdiccional Disciplinaria- la función de "dirimir los conflictos de competencia que ocurran entre las distintas jurisdicciones".

Así las cosas, la Corte Suprema de Justicia dirime los conflictos que surjan entre tribunales superiores de Distrito Judicial, pero no puede hacer lo propio cuando la discrepancia sobre competencia se manifiesta entre un tribunal de distrito judicial y uno Contencioso Administrativo. En éste último caso, tampoco el Consejo de Estado podría resolver. Y, por tanto, la superioridad funcional común es la Corte Constitucional. ${ }^{11}$
En dicha ocasión, la Corte revisó la colisión de competencias suscitada entre dos juzgados civiles de igual jerarquía, concretamente, juzgados civiles del Circuito, los cuales pertenecían a diferentes distritos judiciales, razón por la cual consideró que es la Corte Suprema, en su Sala de Casación Civil, la encargada de dirimir tal conflicto, y por lo tanto, remitió las actuaciones a dicha Corporación.

Ahora bien, con la entrada en vigencia del Decreto 1382 de 2000, el cual dispone las reglas básicas de reparto en materia de acción de tutela, la Corte Constitucional, profirió el Auto 085 de 2000, en donde estableció:

Como es suficientemente conocido, para garantizar el imperio de la Constitución Política, además de la acción pública que para el efecto consagra como un derecho político de los ciudadanos en su artículo 40 , numeral $6^{\circ}$, la Carta instituye otros mecanismos como sucede con el control automático de constitucionalidad en los casos por ella previstos $\mathrm{y}$, además, expresamente dispone que "en todo caso de incompatibilidad entre la Constitución y la Ley u otra norma jurídica, se aplicarán las disposiciones constitucionales", (artículo 4º), institución esta conocida como la "excepción de inconstitucionalidad", que ya consagraba en el Derecho Colombiano el artículo 215 de la Constitución anterior. $^{12}$

Posteriormente, en el mismo auto anotado, la corporación constitucional, consideró:

Con absoluta transparencia se observa que el Decreto 1382 de 12 de julio de 2000, publicado en el Diario Oficial No. 44.082 del viernes 14 de julio del mismo año, en su artículo $1^{\circ}$ a pretexto de ejercer la potestad reglamentaria que corresponde al Presidente de la República conforme al numeral 11 del artículo 189 de la Constitución Política, lo que en realidad hace es introducir modificaciones al artículo 37 del Decreto 2591 de 1991 en materia de competencia para conocer de la acción de tutela. En efecto:

10 CCons, Auto 020/1996, elCC-010, J, Hernández

11 CCons, Auto 044/1998, elCC-024, J, Hernández

12 CCons, Auto 085/2000, elCC-118, A, Beltrán. 
6.1. Mientras el artículo 37 del Decreto 2591 de 1991 establece que para el conocimiento de dicha acción tienen competencia, "a prevención, los jueces 0 tribunales con jurisdicción en el lugar donde ocurriere la violación o la amenaza que motivaren la presentación de la solicitud", el Decreto 1382 de 12 de julio de 2000 fija unas reglas nuevas de competencia teniendo en cuenta para ello si la acción de tutela se interpone contra cualquier autoridad pública nacional, departamental o municipal, hipótesis en las cuales la acción habrá de ejercerse en unos casos ante los Tribunales Superiores de Distrito Judicial, Administrativos y Consejos Seccionales de la Judicatura, en otros ante los Jueces del Circuito o con categoría de tales, en algunos otros casos ante los Jueces Municipales y, además, se agrega que cuando la acción se dirija en relación con "la aplicación de un acto administrativo general dictado por una autoridad nacional serán repartidas para su conocimiento al Tribunal Contencioso Administrativo de Cundinamarca, siempre que se ejerzan como mecanismo transitorio para evitar un perjuicio irremediable".

6.2. Adicionalmente, el artículo $1^{\circ}$ del citado Decreto 1382 de 2000 establece que si la acción de tutela se ejerce "contra más de una autoridad" el asunto será de conocimiento del "juez de mayor jerarquía", según corresponda al nivel de las autoridades respecto de las cuales se impetra la protección de derechos fundamentales vulnerados 0 amenazados de vulneración.

6.3. Por otra parte, el numeral $2^{\circ}$ del artículo $1^{\circ}$ del Decreto 1382 de 2000, dicta nuevas normas que fijan la competencia para los casos en que la acción de tutela se incoe contra funcionarios o corporaciones judiciales.

7. Así las cosas, para la Corte es claro que el Presidente de la República carece de competencia para introducir modificaciones al artículo 37 del Decreto 2591 de 1991, como las que efectivamente introdujo a esa norma legal mediante el artículo $1^{\circ}$ del Decreto 1382 de 2000, pues ello corresponde al Congreso de la República mediante ley, conforme a lo preceptuado en el artículo 150 de la Carta Política.

8. Pero es más. Mientras el artículo 86 de la Carta instituye como un derecho de toda persona ejercitar la "acción de tutela para reclamar ante los jueces, en todo momento y lugar" para impetrar la protección inmediata de los derechos fundamentales vulnerados 0 amenazados de vulneración, el artículo $1^{\circ}$ del Decreto 1382 de 12 de julio de 2000 limita ese derecho con la asignación de competencia a distintos funcionarios judiciales teniendo en cuenta la categoría de las autoridades públicas contra las cuales pueda dirigirse la petición de amparo, lo que significa que ya no podrá entonces el afectado ejercitar tal acción ante cualquier juez, en cualquier momento y en todo lugar como expresamente lo dispuso el citado artículo 86 de la Constitución.

Siendo ello así, surge de bulto que el artículo $1^{\circ}$ del Decreto 1382 de 12 de julio de 2000, fue mucho más allá de la usurpación al Congreso de la República para introducir modificaciones al artículo $37 \mathrm{del}$ Decreto 2591 de 1991, para reformar, sin atribución alguna el artículo 86 de la Constitución Política, pues esa reforma no se ciñe para nada a ninguno de los procedimientos que para el efecto se establecen en el Título XIII de la Constitución (artículos 374 a 379).

Finalmente, en el decisum del Auto, dispuso, entre otros mandatos, "Inaplicar, en relación con las acciones de tutela a que se refiere esta providencia el artículo $1^{\circ}$ del Decreto 1382 de 12 de julio de 2000, por ser contrario a la Constitución Política conforme a lo expuesto en la parte motiva de este auto." Y por lo tanto, dirimió el conflicto planteado.

Posteriormente, la Corte analizó un particular conflicto negativo de competencias entre tres autoridades judiciales, el Juzgado Cuarto de Familia de Armenia, la Sala de Casación Penal y la Sala de Casación Civil de la Corte Suprema de Justicia, toda vez que no existe un superior jerárquico funcional común entre estas dos últimas autoridades judiciales, la Corte determinó que a ella le corresponde resolver el conflicto planteado. Para ello, concluyó aduciendo:

Teniendo en cuenta que la acción de tutela de la referencia fue presentada ante el juez del lugar donde ocurrieron los hechos, la Corte declarará que el Juzgado Cuarto de Familia de Armenia, es el competente para darle trámite, de conformidad con lo dispuesto en la norma antes citada. ${ }^{13}$ 
Dicho Auto, al igual que en el 087 de 2001, inaplicó por inconstitucional el artículo 1 del Decreto 1382 de 2000, destacando que tal disposición:

No es aplicable al caso presente, en cuanto que el mismo modifica lo dispuesto por los artículos 86 de la Constitución Política y 37 del Decreto 2591 de 1991, restringiendo irrazonablemente el derecho de acceso a la administración de justicia. En realidad -lo ha dicho esta Corporación-, la norma aplicable para efectos de determinar la competencia en sede de tutela es el citado artículo 37 del Decreto 2591 de 1991, según el cual, '[s]on competentes para conocer de la acción de tutela, a prevención, los jueces o tribunales con jurisdicción en el lugar donde ocurriere la violación o la amenaza que motivaren la presentación de la solicitud'.

Más tarde, mediante Auto 159A de 2003, la Corte Constitucional, a pesar de analizar un caso en donde existía un superior común de las autoridades judiciales en conflicto, consideró que la resolución de los conflictos de competencia debe atender los principios eficacia de los derechos fundamentales, es decir, la prevalencia de derecho substancial sobre el procedimental, la sumariedad, celeridad e informalidad del procedimiento de tutela. Concluyó, argumentando:

En virtud de los principios de eficacia de los derechos fundamentales, de prevalencia del derecho sustancial sobre el procedimental y de celeridad e informalidad del trámite de tutela, la Corte entrará a proteger el derecho al acceso oportuno a la administración de justicia de la ciudadana Hilda María Ordóñez González y se abstendrá de prolongar la definición en punto de competencia para el conocimiento de la acción de tutela, para lo cual entrará a resolver el conflicto de competencia de la referencia. ${ }^{14}$

Tal posición fue reiterada en Auto 023 de 2004, en donde resolvió de manera atenuada, el conflicto de competencia presentado entre el Juzgado 2 Penal del Circuito de Andes -Antioquia- y el Juzgado 11 Penal del Circuito de Medellín, despachos que para el efecto, gozaban de superior jerárquico común. En esa oportunidad la Corte consideró, luego de citar el auto mencionado, que por el transcurso del tiempo desde la fecha en que se interpuso la acción de tutela, hasta la fecha en que la Corporación tiene conocimiento de la colisión de competencia, es ella la encargada de resolver el conflicto planteado.

Más adelante, en Auto 003 de 2006, en relación con un conflicto de competencia entre Juzgado Diecinueve (19) Civil del Circuito de Bogotá y el Juez Veintitrés (23) Penal del Circuito de Bogotá, la Corte Constitucional, consideró:

Como ha sido ampliamente expresado en diversos fallos, esta Corporación ha acogido tanto la aplicación de la regla general de resolución de conflictos de competencia que se susciten entre diversas instancias judiciales de la misma especialidad, y que en materia de tutela, se ha interpretado como que dichos conflictos deben ser resueltos por su superior jerárquico común funcional - si este existe -; así como también ha establecido que si bien no existe norma que lo disponga de manera expresa, resulta razonable acudir a la aplicación extensiva de lo establecido en el artículo 18 de la Ley 270 de 1996, determinándose que lo dispuesto allí es aplicable para los conflictos de competencia en materia de acciones de tutela. Por lo que la competencia de la Corte en esta materia se da de manera residual, presentándose sólo frente a la imposibilidad de resolución de un conflicto de competencia por medio de las formulas anteriores.

2. Atendiendo entonces a lo dispuesto en el mencionado artículo 18 de la Ley 270 de 1996 y al criterio funcional de la jurisdicción constitucional, en el presente conflicto de competencia se encuentra que el Juzgado Diecinueve (19) Civil del Circuito de Bogotá y el Juzgado Veintitrés (23) Penal del Circuito de Bogotá, no tienen superior jerárquico común funcional. Pues cada uno de los jueces en mención tiene como superior funcional, según el artículo 18 de la ley 270 de 1996, la Sala correspondiente del Tribunal Superior. Además, no existen en el mencionado Tribunal salas mixtas en las que converjan las distintas materias de la jurisdicción ordinaria, ni decisión de la Corte Suprema de Justicia que reconozca competencia funcional en esta materia. Debido a esto, la Corte

14 CCons, Auto 159/2003, elCC-711, E, Montealegre. 
aplicará el criterio funcional correspondiente a la jurisdicción constitucional, en atención a que los jueces mencionados obran en el presente proceso como jueces de tutela luego su ejercicio se despliega dentro de la jurisdicción constitucional en comento. En dicho orden, es a la Corte Constitucional - como tribunal vértice de la mencionada jurisdicción constitucional - a quien corresponde desatar el presente conflicto de competencia.

En esta medida, empieza a tornar mayor importancia el mandato superior cuya doctrina expone que es la Corte Constitucional el máximo órgano de la jurisdicción constitucional, de manera que todas las actuaciones y conflictos que devengan de acciones constitucionales, serán tratados por dicha corporación, incluidos los conflictos de competencia en materia de acción de tutela, atendiendo el origen constitucional de ésta última.

De igual manera, en Auto 213 de 2007, a partir de un conflicto de competencia entre el Juzgado Cuarenta Penal del Circuito de Bogotá y el Juzgado Quinto Penal del Circuito de Cartagena (Bolívar), la Corte reiteró lo dispuesto en el Auto 170 de 2003, concluyendo que

En aplicación de la posición reiterada de la Sala en el sentido de que la Corte no puede ser permisiva con la dilación de los términos ni con la renuencia de las autoridades a asumir de manera definitiva el conocimiento de las solicitudes de tutela," previene a la señora Juez Cuarenta Penal del Circuito de Bogotá para que se abstenga en el futuro de adoptar decisiones como la que motivó la controversia procesal dentro del trámite constitucional de la referencia. ${ }^{15}$

Para el año 2009, la Corte profirió el Auto 124 de 2009, mediante el cual se establecieron las respectivas reglas, como consecuencia natural de la multiplicidad de pronunciamientos proferidos por la corporación, así:

(i) Un error en la aplicación o interpretación de las reglas de competencia contenidas en el artículo 37 del decreto 2591 de 1991 puede llevar al juez de tutela a declararse incompetente (factor territorial y acciones de tutela que se dirijan contra los medios de comunicación). La autoridad judicial debe, en estos casos, remitir el expediente al juez que considere competente con la mayor celeridad posible.

(ii)Una equivocación en la aplicación o interpretación de las reglas de reparto contenidas en el Decreto 1382 de 2000 no autorizan al juez de tutela a declararse incompetente y, mucho menos, a declarar la nulidad de lo actuado por falta de competencia. El juez de tutela debe, en estos casos, tramitar la acción 0 decidir la impugnación, según el caso.

(iii) Los únicos conflictos de competencia que existen en materia de tutela son aquéllos que se presentan por la aplicación 0 interpretación del artículo 37 del Decreto 2591 de 1991 (factor territorial y acciones de tutela que se dirijan contra los medios de comunicación).

Estos serán decididos, en principio, por el superior jerárquico común de las autoridades judiciales involucradas 0 , en su ausencia, por la Corte Constitucional en su calidad de máximo órgano de la jurisdicción constitucional, de conformidad con las reglas jurisprudenciales que hasta el momento se han venido aplicando en esta materia.

(iv) Ninguna discusión por la aplicación 0 interpretación del Decreto 1382 de 2000 genera conflicto de competencia, ni siquiera aparente. Por tanto, en el caso de que dos autoridades judiciales promuevan un conflicto de competencia por este motivo, el expediente será remitido a aquella a quien se repartió en primer lugar con el fin de que la acción de tutela sea decidida inmediatamente, sin que medien consideraciones adicionales relativas a las normas de reparto. Lo anterior no obsta para que esta Corporación o el superior funcional al que sea enviado un supuesto conflicto de competencia, proceda a devolver el asunto, conforme a las reglas de reparto del Decreto 1382 de 2000, en aquellos supuestos en que se presente una distribución caprichosa de la acción de tutela fruto de una manipulación grosera de las reglas de repartos contenidas en el mencionado acto administrativo, como sería el caso de la distribución equivocada de una acción de tutela

15 CCons, Auto 213/2007, e ICC-1137, J, Córdoba. 
interpuesta contra una providencia judicial emanada de una de las Altas Cortes. ${ }^{16}$

Más adelante, mediante Auto 200 de 2009, en conflicto suscitado entre el Juzgado Treinta y Ocho Administrativo del Circuito de Bogotá y el Juzgado Tercero Administrativo del Circuito de Popayán, la Corte Constitucional, además de resolver el conflicto de competencia, consideró:

No obstante y en atención a los principios de celeridad, eficacia, acceso oportuno a la administración de justicia y el respeto por los derechos fundamentales, la Sala Plena puede conocer y resolver directamente los conflictos que se presenten entre autoridades judiciales que posean un superior jerárquico común.

Ahora bien, las normas que determinan la competencia en materia de tutela, son el artículo 86 de la Carta Política y el artículo 37 del Decreto 2591 de 1991. Por su parte, el Decreto 1382 de 2000 establece las "reglas para el reparto de la acción de tutela" y no las que definen la competencia de los despachos judiciales, pues por su inferioridad jerárquica frente a las anteriores disposiciones, no puede modificarlas. Este último, fue inaplicado en numerosas oportunidades por la eventual incompatibilidad de las disposiciones en él contenidas frente a la Carta Política. ${ }^{17}$

Finalmente, mediante Auto 045 de $2010^{18}$, la Corte dirimió Conflicto de Competencia entre el Juzgado Primero Penal Municipal con funciones de conocimiento de Palmira y el Juzgado Séptimo Penal Municipal con funciones de conocimiento de Cali, con las mismas consideraciones esbozadas en el Auto inmediatamente anterior.

\section{POSICIÓN CORTE SUPREMA DE JUSTICIA}

Es entonces como dentro de un conflicto de competencia suscitado entre el Tribunal Superior de Antioquia y Tribunal Superior de Santa Fe de Bogotá, en sus salas Penales, la H. Corte Suprema de Justicia toma como fundamento el artículo 37 del Decreto 2591 de 1991, el cual dispone:

Que son competentes para conocer de las acciones de tutela a prevención, los jueces o tribunales con jurisdicción en el lugar donde ocurrió la violación 0 amenaza que da lugar a la presentación de la solicitud de amparo, es decir, dicha norma autoriza al actor para que escoja, entre los jueces, a cuál de ellos le formula la petición de protección de sus derechos". Por lo tanto el Tribunal competente para decidir es el de Antioquia debido a que allí es donde le fueron violados los derechos fundamentales al autor, y no en Santa fe de Bogotá. ${ }^{19}$

Se observa con lo anterior, que uno de los factores analizados por parte de la indicada corporación con relación al conflicto suscitado, se resuelve fácilmente aplicando al artículo 37 del Decreto 2591, otorgando así la competencia al juez en donde ocurrieron los hechos por medio de los cuales se consideraron vulnerados los derechos fundamentales del actor. Para ello, entendemos que la Corte dirimió el conflicto en su calidad de superior jerárquico, tal y como lo prescriben las normas del Código de Procedimiento Civil.

Ahora bien, en esa misma línea de tiempo, la Corte comienza a crear una reglamentación eminentemente pretoriana, en donde por medio de precedentes y aplicación del principio de la analogía, en el año de 1997 manifestó:

Aunque no existe previsión expresa en torno a las diferencias de criterio que puedan surgir entre las autoridades judiciales para conocer de esta extraordinaria acción constitucional, lo cierto es que este tipo de conflictos no pueden ser ajenos al trámite tutelar y en tales eventos -como en todos los restantes de vacío legislativo- ha de acudirse a la regulación que al efecto se haga en el ordenamiento procesal ordinario, por virtud del principio de integración jurídica.

16 CCons, Auto 124/2009, elCC-1404, H, Sierra.

17 CCons, Auto 200/2009, elCC-1431, JI, Palacio.

18 CCons, Auto 045/2010, elCC-1463, GE, Mendoza.

19 CSJ, T- 877/ 26-04-94, G, Gómez 
Posteriormente, argumentó que debido a que no se puede obstruir el curso procesal de la tutela por la existencia de una anomia, y con el propósito de imprimir mayor celeridad y eficacia al trámite constitucional, el organismo competente para dirimir el conflicto

Atendiendo el trámite preferente y sumario propio de la acción de tutela, las divergencias que en torno a la competencia para conocer de la misma se originen entre los jueces de la República, deben ser resueltas de plano por el Superior de los funcionarios trabados en el conflicto, dentro del marco de celeridad que debe caracterizar la aplicación de este informal mecanismo para prohijar derechos fundamentales. ${ }^{20}$

La Corte Suprema de Justicia, siendo consecuente con lo proferido desde el año 1992 con relación a la definición de competencias según el criterio o factor territorial, es decir, según el lugar de la ocurrencia del hecho vulnerador del derecho fundamental en cuestión, en el año de 1999 afirma y dirime una colisión de competencia, argumentando:

Una de las formas como a las claras se ve la pérdida de la característica de celeridad que tiene la tutela es precisamente cuando del conocimiento de la acción se apartan los jueces propiciando la intervención del Superior en procura de la solución al conflicto casi siempre generado a raíz del factor competencia a prevención asignado "a los jueces o Tribunales en el lugar donde ocurriere la violación o la amenaza que motivara la presentación de la solicitud. - artículo 37 del Decreto 2591 de 1991-.

Por tal razón esta Colegiatura teniendo en cuenta que los juzgados en discordia pertenecen a distritos diferentes, por vía de la jurisdicción ordinaria resuelve el asunto.

Si ello es así significa que independiente al lugar donde deben cumplirse tareas complementarias con miras a la materialización de la obtención del documento, el génesis de la supuesta vulneración del derecho tiene asiento en donde dejó de acatarse el normal desarrollo del trámite previsto. ${ }^{21}$
Un año más tarde, la Corte realiza el estudio de un conflicto de competencias, en donde arguyó que tendrán la competencia para decidir sobre la acción de tutela aquellos jueces o tribunales con jurisdicción donde ocurra la violación o amenaza que motiva la solicitud de amparo, para el efecto, expresando, que:

Vale decir, la actitud del Tribunal Superior de Santa Fe de Bogotá no debió ser la de provocar conflicto alguno y remitir el expediente a la CORTE, sino devolverlo ante quien fue presentada la tutela, por haberse radicado allí la competencia, dada la escogencia que el accionante hizo. Basta saber que ésta manifiesta estar domiciliada en Moniquirá (Boyacá), donde labora y recibe su salario, respecto del cual reclama un tratamiento igualitario a los del resto de servidores públicos a quienes sí se les reajustó el mismo. ${ }^{22}$

Consecuentemente, la sentencia T-10197/01 acoge al argumento de la anterior decisión, con la particularidad de un salvamento de voto, en el que explica que dicha actuación no se deja al libre albedrío del usuario de la justicia, en tanto que según "[l]o dispuesto en el artículo 37 lo que regula es otra cosa, esto es, la competencia a prevención pero dentro de los jueces o tribunales existentes 'en el lugar donde ocurriere la violación o la amenaza que motivaren la presentación de la solicitud', que son los competentes para conocer de ella, pues por esto es que la norma dispone integralmente, que "[s]on competentes para conocer de la acción de tutela, a prevención, los jueces o tribunales con jurisdicción en el lugar donde ocurriere la violación o la amenaza que motivaren la presentación de la solicitud", es decir, que entre ellos el accionante puede escoger uno, pero insistimos, nunca que puede elegir cualquiera del país.

Aquí se está consagrando la competencia territorial y por ende, el juez natural, y éste no puede ser desconocido en un Estado de Derecho por ningún motivo, no hay informalidad que valga para 
justificar su cambio, pues en el momento en que el juez pueda ser escogido, la seguridad jurídica de los destinatarios de la ley queda absolutamente desprotegida y la legitimidad del estado cuestionada.

La Corte Suprema de Justicia, en numerosos pronunciamientos proferidos en la época, presentó sus argumentos en la misma corriente expuesta, tal y como puede observarse en la sentencia T11366 / 30-05-02 Magistrado Ponente Álvaro Orlando Pérez Pinzón, en donde se manejan textual y jurídicamente los mismos fundamentos de los anteriores fallos en torno a la solución de conflictos de competencia en materia de tutela.

Durante los años 2003 y 2004 la visión jurídica de dicha corporación se encamina dentro del mismo fenómeno argumentativo ya expuesto, es decir, el factor territorial. Para ello, anotó que:

El conflicto planteado debe resolverse, como la plantea el Juzgado de Cali, con sustento en el decreto 1382 de 2000, el cual recobró su vigencia el 16 de marzo de 2002. Según el inciso $1^{\circ}$ de su artículo $1^{\circ}$ conocen "a prevención" de la acción de tutela "Ios Jueces con jurisdicción donde ocurriere la violación o la amenaza que motivare la presentación de la solicitud o donde se produjeren sus efectos.

Esto quiere decir que en el presente caso los Juzgados que trabaron la colisión son, en principio, competentes para conocer del asunto. El de Cali, porque es donde tuvo ocurrencia el supuesto acto arbitrario de la entidad demandada; y el de Bogotá, que es donde reside la accionante, porque es el lugar donde se produjeron sus efectos. No obstante, el despacho judicial competente "a prevención" para asumirlo es el de Bogotá, sencillamente porque es la ciudad donde tuvo lugar la presentación de la demanda ${ }^{23}$

Para una mayor claridad al respecto, la Corte consideró:

Conforme lo dispone el artículo 37 del Decreto 2591 de 1991, con la modificación que le introdujo el artículo 1 del Decreto 1382 de 2000, de la solicitud de amparo constitucional conoce:
El Juez con jurisdicción donde ocurrió la violación o la amenaza que 'motivare la presentación de la solicitud'. 0, El funcionario judicial con jurisdicción donde se produjeren los efectos de la vulneración 0 puesta en peligro del derecho fundamental.

3. De esa forma quedó resuelta a nivel normativo una dilatada polémica en la jurisprudencia, ofreciéndole al usuario del servicio público de administración de justicia la opción de optar por un Juez que siendo competente por la naturaleza del asunto - como aquí ocurre - no pudiera excusar su competencia por tener que decidir entre el lugar donde ocurrió la supuesta violación que motiva la presentación de la acción o donde se manifiestan sus efectos sobre sus derechos fundamentales.

Con el fin de adoptar la decisión a que haya lugar, señálese que conforme a los parámetros que brindan los artículos 37 del Decreto 2591 de 1991 y $1^{\circ}$ del Decreto 1382 de 2000, son competentes para conocer de la acción de tutela, a prevención, los jueces o tribunales con jurisdicción en el lugar donde ocurrió la violación o amenaza para los derechos fundamentales, concepto que como lo ha precisado la Sala Plena de esta Corporación en múltiples ocasiones, no se circunscribe de manera exclusiva a aquél en donde se produjo la acción u omisión que origina la solicitud de amparo, ni tampoco al domicilio de la entidad accionada, sino que se extiende al sitio donde se proyectan sus efectos por cuyo medio se amenazan 0 vulneran derechos fundamentales.

En la misma dirección se ha precisado además, que por virtud de la expresa referencia al factor 'competencia a prevención', destacado normativamente como criterio rector para definir este aspecto en materia de tutela, es competente para conocer de ella el juez ante quien se formula la demanda, siempre que, claro está, de dicho lugar resulte predicable la ocurrencia del quebranto 0 la de sus efectos.

Los anteriores criterios, han sido aclarados por la Corte Constitucional en el siguiente sentido:

Como se presenta en el asunto de la referencia, puede ocurrir que se verifiquen varias de las

23 CSJ, T- 18508 /10-11-04, Y, Ramírez. 
alternativas enunciadas y en esa medida tanto el Juzgado Segundo Promiscuo de Familia de Socorro y el Juzgado Cuarto del Circuito Judicial Administrativo de Bucaramanga, pueden ser competentes en el trámite de la presente acción. En efecto, en el municipio del Socorro se encuentra el inmueble que supuestamente presenta fraudes de energía; pero por otro lado, se observa en el expediente que el accionante alega la vulneración de su debido proceso y ha presentado varios derechos de petición ante la Electrificadora de Santander en Bucaramanga, solicitando se le garantice el derecho a la defensa, mediante la notificación del trámite administrativo.

4.- En este tipo de casos la Corte Constitucional ha fijado la regla jurisprudencial según la cual el criterio que deben aplicar los jueces 0 tribunales antes de abstenerse de asumir el conocimiento de una solicitud de amparo constitucional, es la elección que haya efectuado el accionante respecto al lugar donde desea se tramite la acción. Lo anterior, a partir de la interpretación sistemática del artículo 86 Superior y del artículo 37 del Decreto 2591 de 1991, que garantizan a todo persona reclamar "ante los jueces - a prevención" la protección inmediata de sus derechos constitucionales fundamentales." Auto 071 de 2007, expediente ICC 1085, 21 de marzo de $2007 .{ }^{24}$

\section{CONCLUSIÓN}

Con respecto a las consideraciones y pronunciamientos tanto de la Corte Constitucional como de la Corte Suprema de Justicia, se observa que no existe legislación alguna que permita dilucidar un enfoque igualitario que desemboque en la unificación de criterios sobre el organismo competente de dirimir las colisiones de competencia fruto de la interposición del mecanismo fundamental.

Al efecto, cabeanotar que cada una de las Corporaciones mencionadas, aborda la temática desde su propio enfoque, y solo hasta el año 2007 la Corte Suprema de Justicia decide citar a la Corte Constitucional con el propósito de dirimir un conflicto de competencia. Es entonces como puede evidenciarse que no existe unanimidad en cuanto al órgano competente para dirimir los conflictos de competencia suscitados con ocasión de la acción de tutela.

Uno de los argumentos que permiten resolver el problema jurídico planteado, además del estudio jurisprudencial realizado, lo constituye la posición del $\mathrm{H}$. Consejo de Estado, en donde argumentó en uno de sus autos, proferido en el año 2001, que:

En el Estado de derecho la posición jurídica del individuo es diametralmente opuesta a la del funcionario público. El individuo puede hacer todo aquello que no le esté expresamente prohibido por la ley. En cambio, el gobernante, la autoridad, actúa siempre con competencias que en principio son limitadas. Al individuo, al ciudadano lo que no le está expresamente prohibido le está permitido. Al funcionario público lo que no le está expresamente atribuido, le está prohibido. Al particular le basta con saber que su conducta no está prohibida para que pueda realizarla; en cambio, al gobernante no le sirve este mismo argumento. Para que él pueda actuar, necesita mostrar la norma que lo faculte para ello; si no existe esa norma, le está prohibida esa actuación. En el Estado de derecho las competencias de la autoridad son siempre expresas, explícitas no existiendo para ello competencias implícitas, ni por analogía y este principio es válido no sólo para el más humilde de los funcionarios, sino también para la Corte Constitucional. La Corte Constitucional, por muy alta que sea su misión es un órgano aplicador de la Constitución y no un órgano creador de la misma, de manera tal que el vacío sobre la falta de competencia para dirimir conflictos de competencia en materia de tutela no puede llenarlo la propia Corte Constitucional, sino que debe ser establecido por el propio constituyente 0 en su defecto por el legislador. La competencia para resolver conflictos de competencia, debe ser expresa y no existe norma constitucional ni legal que la atribuya a la Corte Constitucional. La falta de norma expresa no puede suplirse con la falacia de que por ser la Corte Constitucional el juez máximo de la jurisdicción constitucional tiene implícitamente esa competencia. ${ }^{25}$ 
Dicho lo anterior, es claro que cada juez que se enfrenta al conocimiento de una acción de tutela, actúa en calidad de juez constitucional, pero, ¿en realidad obedece a una jurisdicción constitucional especializada, verbigracia, laboral, civil, penal, entre otras? ¿La posición de la Corte Constitucional contravía el derecho fundamental al debido proceso y limita excesivamente la seguridad jurídica? Son estos interrogantes los que dilucidan y sitúan en una real tela de juicio el concepto de "jurisdicción constitucional" del que tanto se habla y escribe en Colombia.

El conflicto de competencia es tan sólo uno de los fenómenos que llegarían a desvirtuar la existencia de una jurisdicción constitucional, toda vez que al existir acciones constitucionales, estas son tratadas por los jueces ordinarios. ¿Podría un juez civil conocer la denuncia del delito tipo de lesiones personales?

Así las cosas, acogiendo la tesis planteada por el Consejo de Estado, la respuesta al problema jurídico planteado es negativa, no puede y no debe la Corte Constitucional conocer los conflictos de competencia a la luz de su propia jurisprudencia sin la existencia de norma expresa que así se lo determine, en tanto que tal actuación contraviene el libre acceso a la justicia a prevención, además del importantísimo respeto al debido proceso, en tanto que la misma norma que regula la acción de tutela, remite a la legislación civil aquellas anomias del tal proceso constitucional y no habilitó a la jurisprudencia como órgano legislador de dicha temática.

Finalmente, y como respaldo a la anterior afirmación, tenemos el salvamento de voto del Magistrado de la Corte Constitucional Jaime Araujo Rentería, del Auto 087 de $2001^{26}$, en donde expresó:

Respetuosamente me permito apartarme de la decisión aprobada por la Sala Plena de la Corte respecto de la resolución del conflicto de competencia ICC-266, por cuanto considero que no existe norma legal que autorice a esta corporación para definir conflictos de competencia en materia de tutela. Los argumentos en que me baso para sostener esta tesis son los que se señalan a continuación.

Bajo ese contexto, y con relación a la colisión de competencias entre funcionarios que pertenecen a diferentes jurisdicciones, el artículo 256-6 del Estatuto Superior, señaló que le corresponde al Consejo Superior de la Judicatura, o a los Consejos Seccionales, según el caso y de acuerdo con la ley, "[d]irimir los conflictos de competencia que ocurran entre las distintas jurisdicciones."

Igualmente, la Ley 270 de 1996, Estatutaria de la Administración de Justicia, al momento de regular la competencia específica de la Sala Disciplinaria del Consejo Superior de la Judicatura, le asignó en el numeral 2 del artículo 112, la siguiente función:

\section{Dirimir los conflictos de competencia que ocurran entre las distintas jurisdicciones, y entre éstas y las autoridades administrativas a las cuales la ley les haya atribuido funciones jurisdiccionales, salvo los que se prevén el artículo 114, numeral tercero, de esta ley y entre los Consejos Seccionales o entre dos salas de un mismo Consejo Seccional.}

Tal disposición que fue objeto de revisión por la Corte Constitucional en la sentencia C-037 de 1996, la cual fue declarada exequible, es decir, que sus efectos siempre han sufrido consecuencias y lo seguirán haciendo por la existencia de la cosa juzgada constitucional.

\section{REFERENCIAS BIBLIOGRÁFICAS}

- Atienza, M. y Ruiz, J. (2009). Dejemos atrás el positivismo jurídico, Para una Teoría postpositivista del derecho. Bogota: Editorial Temis

- Blanco, R. (1998). El valor de la constitución. Madrid: Alianza Universidad.

- Camargo, M. (2011). Decretos - leyes y jurisdicción constitucional: Estudios comparados, España: Editorial Universidad de Salamanca. 
- Carbonell, M. (2005). Nuevos tiempos para el constitucionalismo, Neoconstitucionalismo(s). ( $\left.2^{\mathrm{a}} \mathrm{ed}\right)$. Madrid: Ed trotta.

- Carbonell Miguel - Leonardo García Jaramillo Editores, "El Canon Neoconstitucional", Universidad Externado de Colombia, 2010.

- Duverger, M. (1968). Constitucionals et Documents Politiquies. París: Presses Universitaires de France.

- Giacomette, A. 2007. La prueba en los procesos constitucionales. Bogotá: Ediciones Uniandes.

- Guastini, R. (1998). Dalle fonti alle norme, Giapichelli, Torino.

- Guastini, R. (2013). Propósito del neoconstitucionalismo, Gaceta Constitucional, Tomo 67, Doctrina Constitucional, Perú.

- Henao, J. (2010). Derecho Procesal Constitucional. ( $\left.3^{\mathrm{a}} \mathrm{Ed}\right)$. Bogotá: Editorial Temis.

- Hoerster, N. (1992). En defensa del positivismo jurídico. Barcelona: Gedisa.

- Prieto, L. (2007). El constitucionalismo de principios, ¿Entre el positivismo y el ius naturalismo?, Derechos fundamentales, neoconstitucionalismo y ponderación judicial. Lima: Ed. Palestra.

- Pulido, C. (2006). El neoconstitucionalismo a debate. ( $\left.1^{\text {a }} \mathrm{Ed}\right)$. Colombia: Instituto de Estudios Constitucionales Carlos Restrepo Piedrahita.

- Quinche, M. (2006). La elusión Constitucional Una Política de evasión del control Constitucional en Colombia. Bogotá: Ediciones Doctrina y Ley.

- Rocco, H. (1972). Tratado de Derecho Procesal Civil, Tomos I Y II, Parte General. Bogotá: Temis. Buenos Aires: De Palma.

- Ran Hirschl. (2004). The Polítical Origins of the New Constitucionalism, University of Toronto, Indiana Journal of Global Legal Studies. Volume 11. Issue 1. Article 4.

- Sáchica, L. (1993). La Corte Constitucional y su Jurisdicción. Bogotá: Temis.

- Gorra, D. (2011). Positivismo jurídico: una opción epistemológica para la interpretación y justificación del Derecho Fundamentos en
Humanidades, Universidad Nacional San Luis, Argentina, Red de Revistas Científicas de América Latina, el Caribe, España y Portugal, , vol. XII, núm. 23, p. 40.

- Santiago, A. (2008). Neoconstitucionalismo, sesión privada del instituto de política constitucional. Disponible en http://ancmyp. org.ar/user/files/02neoconstitucionalismo.pdf. Consultado Diciembre 2012.

- Gil, R. El neoconstitucionalismo y los derechos fundamentales, Instituto de Investigaciones Jurídicas de la UNAM. Disponible en http:// www.juridicas.unam.mx/publica/librev/rev/ qdiuris/cont/12/cnt/cnt3.pdf. Consultado Enero 2013.

- Carbonell, M. ¿Qué es una Constitución?, IIJUNAM, Docencia, recuperado de: http://www. miguelcarbonell.com/docencia/que_es_una_ Constitucion.shtml. Consultado Enero 2013.

\section{REFERENCIAS JURISPRUDENCIALES}

\section{Corte constitucional}

- CCons, C-040/1997, A. Barrera.

- CCons, C-111/2000, Á. Tafur.

- CCons, C-1541/2000, C. Gaviria.

- CCons, T-877/1994, G. Velásquez.

- CCons, T- 3318/1997, F. Arboleda

- CCons, Auto 014/1994, e37837. J, Arango.

- CCons, Auto 017/1995, e37837. J, Arango.

- CCons, Auto 020/1996, elCC-010, J, Hernández

- CCons, Auto 044/1998, elCC-024, J, Hernández

- CCons, Auto 085/2000, elCC-118, A, Beltrán.

- CCons, Auto 088/2001, elCC-247, R, Escobar.

- CCons, Auto 159/2003, elCC-711, E, Montealegre.

- CCons, Auto 213/2007, e ICC-1137, J, Córdoba.

- CCons, Auto 124/2009, elCC-1404, H, Sierra.

- CCons, Auto 200 de 2009, e ICC-1431, J, Palacio.

- CCons, Auto 045 de 2010, e ICC-1463, G, Mendoza. 


\section{Corte Suprema de Justicia}

- CSJ T-5496/12-04-99, J, Gómez.

- CSJ T-4970/11-04-00, C, Nader.

- CSJ, (T- $18508 / 10-11-04)$, Y, Ramírez.

- CSJ, T- 33432 / 23-10-07, J, Zapata.

\section{Consejo de Estado}

- CE, Auto 087 de 2001, C,Arciniega.

- CE $2^{\mathrm{a}} 10$ jul. 2013, r 00815-00, G, Gómez. 